\title{
Международный научно-практический семинар «Закономерности трансформации экологических функций геосфер крупных горнодобывающих регионов»
}

\author{
(2021 И. И. Косинова \\ Воронежсский государственный университет, \\ Университетская пл., 1, 394018, Воронеж, Российская Федерация
}

\begin{abstract}
Для цитирования: Косинова И. И. Международный научно-практический семинар «Закономерности трансформации экологических функций геосфер крупных горнодобывающих регионов» // Вестник Воронежского государственного университета. Серия: Геология. 2021. №3. С. 104-107. DOI: https://doi.org/10.17308/geology.2021.3/3656
\end{abstract}

\section{International scientific and practical seminar "Regularities of the transformation of ecological functions of geospheres of large mining regions"}

\begin{abstract}
@2021 I. I. Kosinova ${ }^{\bowtie}$
Voronezh State University, 1 Universitetskaya pl., 394018, Voronezh, Russian Federation

For citation: I. I. Kosinova International scientific and practical seminar "Regularities of the transformation of ecological functions of geospheres of large mining regions". Vestnik Voronezhskogo gosudarstvennogo universiteta. Seriya: Geologiya - Proceedings of Voronezh State University. Series: Geology, 2021, no. 3, pp. 104-107. DOI: https://doi.org/10.17308/geology.2021.3/3656

Conflict of interests: The authors declare the absence of obvious and potential conflicts of interest related to the publication of this article.
\end{abstract}

С 19 по 25 июля 2021 г. на площадке Воронежского государственного университета проходил международный научно-практический семинар на тему «Закономерности трансформации экологических функций геосфер крупных горнодобывающих регионов». Данный семинар проходил в рамках одноименного международного гранта, который выполняется Воронежским государственным университетом, а также Гомельским государственным университетом имени Франциска
Скорины (Республика Беларусь). Семинар проводится при поддержке: Российского фонда фундаментальных исследований, договор №__20-55-00010 от 30.04.2020г. и Белорусского республиканского фонда фундаментальных исследований, договор №X20Р-284 от 04.05.2020 г. Для участия в мероприятии в Воронеж прибыла делегация белорусской стороны, которая включала руководителя гранта от Белоруссии, заведующего кафедрой геологии и географии доктора

\footnotetext{
${ }^{\bowtie}$ Косинова Ирина Ивановна, e-mail: kosinova777@yandex.ru
} 
Павловского А.И. и молодых коллег, преподающих на кафедре геологии и географии данного университета. Семинар проходил в достаточно динамичном формате. Первый день 19 июля представлял собой пленарное заседание, в рамках которого выступили научные руководители и основные исполнители Гранта. Профессор Косинова И. И. в своем докладе доложила результаты эколого-геохимических исследований крупного горнодобывающего района КМА - Губкинского-Старооскольского горнопромышленного района. Была представлена серия тематических карт эколого-геохимического содержания с выделением ведущих компонентов загрязнителей, которые формируются в результате горнодобывающей деятельности. Среди них молибден, бор, кобальт, галлий. Ирина Ивановна подчеркнула, что при формировании эколого-геохимических аномалий в горнопромышленных районах ведущую роль играют не столь горнодобывающие комплексы, а приуроченные к ним перерабатывающие предприятия. Например, в районе известкового завода, который представляет собой элемент электрометаллургической переработки сырья (Оскольский электрометаллургический комбинат), фиксируется визуальная деградация пшеничного поля, располагающегося в непосредственной близости от завода.

Весьма интересные результаты были получены в результате работы по гранту в направлении экологогеофизического преобразования литосферы. Результаты этих исследований доложила руководитель лаборатории глубинного строения, геодинамики и сейсмического мониторинга им. А. Таркова доцент Надежка Л. И. Она отметила, что в разные годы в регионе производится от 350 до 500 промышленных взрывов при добыче полезных ископаемых. При этом происходит целый ряд негативных явлений, таких как нарушение природных гидрогеологических режимов подземных вод из-за образования депрессионных воронок вокруг карьеров, значительное загрязнение подземных и поверхностных вод. Возникающие при взрывах газопылевые облака существенно влияют на состояние атмосферы, кроме того, крупные взрывы нарушают природный ландшафт, способствуют образованию оползней, обвалов. В докладе И. Н. Сафронича подчеркнуто, что в широком спектре экологогеологических факторов, возникающих при проведении промышленных взрывов и влияющих на литосферу, среду обитания и здоровье человека, особое место занимают сейсмические воздействия. Значительный поток сейсмической энергии, возникающий при взрывах, распространяясь в неоднородной геологической среде, создает предпосылки возникновения природно-техногенных землетрясений (наведенной сейсмичности). Сейсмические воздействия, возникающие при проведении промышленных взрывов, распространяются на сотни км, меняют частотный состав фоновых микросейсмических колебаний, тем самым, влияют на комфортность среды обитания и здоровье человека. Регулярность проведения промышленных взрывов, способствует накоплению деформаций в зданиях, сооружениях, коммуникациях, системах жизнеобеспечения, что приводит к преждевременному их разрушению. Значительное увеличение интенсивности колебаний в диапазонах частот, близких к частотному диапазону колебаний человеческого организма приводит к возникновению негативных явлений, а регулярное повторение сейсмических воздействий ведет к ухудшению здоровья человека.

Также большой интерес представляли доклады белорусской стороны: профессора Павловского А. И. и доцента Адрушко С. В. (Гомельский государственный университет им. Ф Скорины), которые продемонстрировали особенности горнодобывающих районов Беларуси. Белорусской Швейцарией называют один из отработанных карьеров, заполненный грунтовыми и атмосферными водами. Вода голубого цвета, очень теплая и чистая, представляет собой место для отдыха горожан, многие приезжают с удаленных концов Белоруссии, чтобы побыть в белорусской Швейцарии. Подобная рекультивация отработанных карьеров широко применяется в настоящее время в мировой практике, формирует природно-техногенные ландшафты. Ученые из Гомельского университета отмечают, что активная разработка месторождений полезных ископаемых приводит как к изменению природного рельефа земной поверхности, так и созданию совершенно новых, техногенных форм рельефа. Важно отметить, что техногенный рельеф отличается своеобразием морфологии и состава отложений, занимает значительные площади часто плодородных земель, способствует развитию опасных геоморфологических процессов. По мере развития горнодобывающей и горноперерабатывающей промышленности, расширения площадей добычи полезных ископаемых растет и разнообразие форм и типов техногенного рельефа, что находит свое отражение в создании большого числа новых классификаций. Формирование техногенного макрорельефа в Республике Беларусь связано с разработкой крупных месторождений полезных ископаемых: месторождение строительного камня «Микашевичи», с крупнейшим на территории Беларуси карьером глубиной свыше 100 м, террасированными склонами; месторождение доломитов «Руба» состоящее из 8 участков, где разрабатывается многоуровневый карьер «Гралево» глубиной более 50 м, обводненный в нижней части. В результате добыча доломита ведется подводным способом.

Активную дискуссию вызвала серия докладов, касающихся безопасности реки Дон. На территории Воронежской области два крупных горнодобывающих предприятия расположены в непосредственной близости от р. Дон. Это ОАО Павловскнеруд и ОАО «Тихий Дон». Профессор ВГУИТ Шахов С. В. обозначил тенденцию интенсивной деградации р. Дон, что проявляется в ее значительном обмелении и загрязнении. В качестве основных причин развития негативных процессов названы, с одной стороны, системы несанкционированного водоотбора речной воды; с другой стороны - сброс в Дон значительного количества загрязненных 
и недоочищенных стоков очистных сооружений, отдельных промышленных предприятий.

В результате работы пленарного заседания были сформулированы основные выводы по работе двух ведущих ВУЗов в рамках международного гранта на тему «Закономерности трансформации экологических функций геосфер крупных горнодобывающих регионов», рассмотрены перспективы дальнейшего развития этой деятельности.

Большой интерес представила серия выездных круглых столов, входящих в программу Семинара. В работе круглых столов приняли участие студенты геологического факультета, профиль - экологическая геология Первый выездной круглый стол проходил на территории Павловского карьера по добыче гранита (рис. 1).

Это крупнейшее горнодобывающее предприятие Воронежской области. Главный геолог карьера, а также доцент геологического факультета ВГУ Дмитриев Д. А. рассказали присутствующим об особенностях истории геологического развития территории, обратили внимание на геологический разрез. Карьер отрабатывается в настоящее время на отметке -70 м, предполагается в дальнейшем углубление до -170 м. Карьер вскрывает около 5 водоносных горизонтов (рис. 2). Вода накапливается в зумпфах на дне карьера (рис. 3). В дальнейшем она насосами поднимается на поверхность и сбрасывается в р. Гаврило.

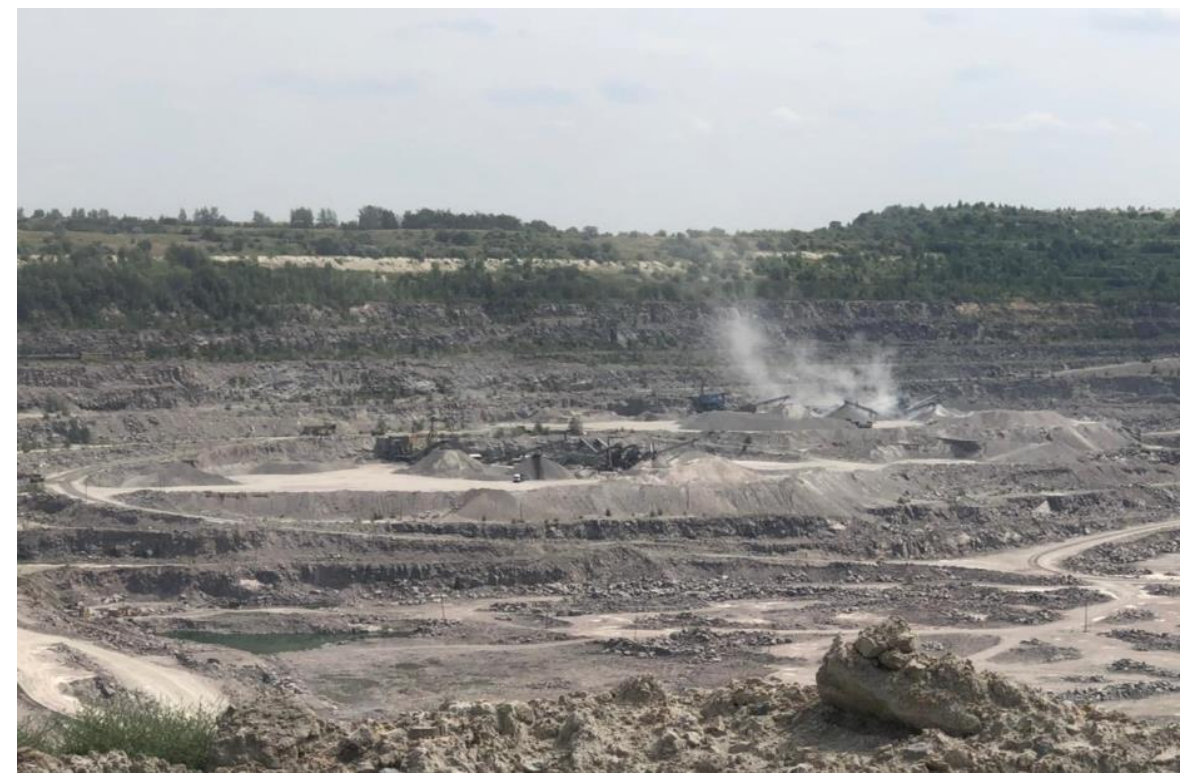

Рис. 1. Павловский карьер по добыче гранита.

[Fig 1. Pavlovsky granite quarry.]

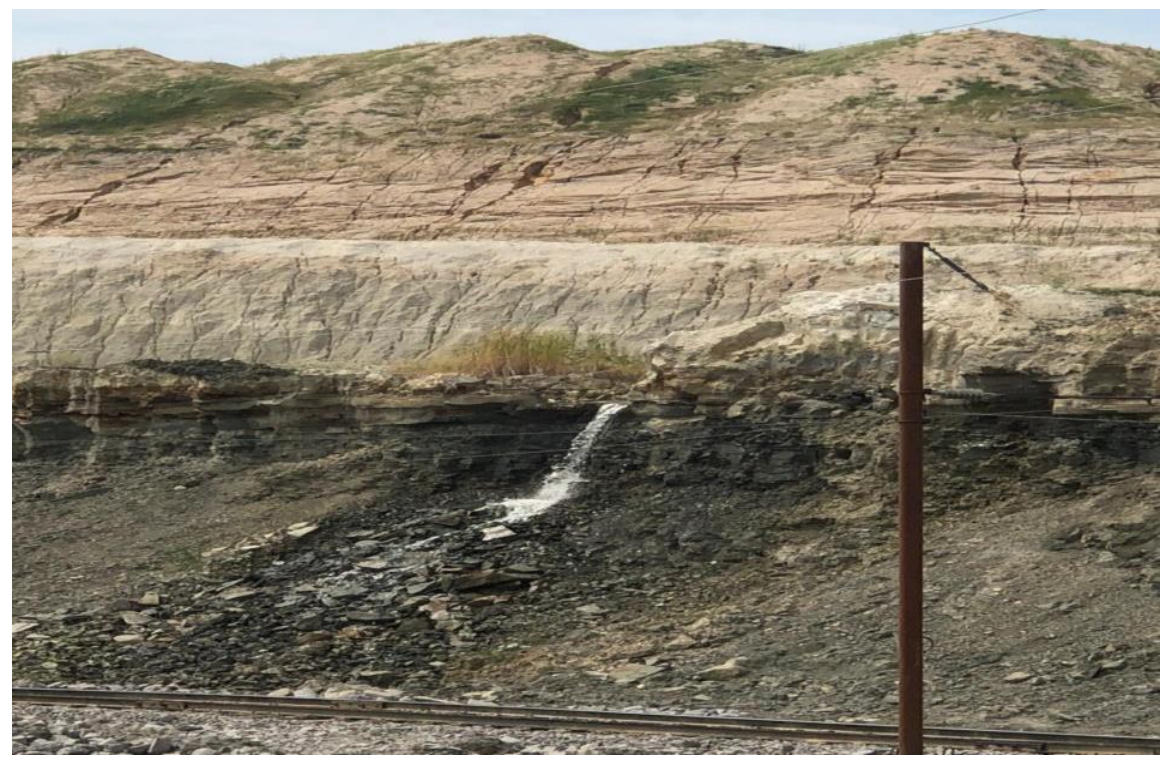

Рис. 2. Дренирование водоносных горизонтов бортами карьера.

[Fig. 2. Drainage of aquifers by the sides of the quarry.] 


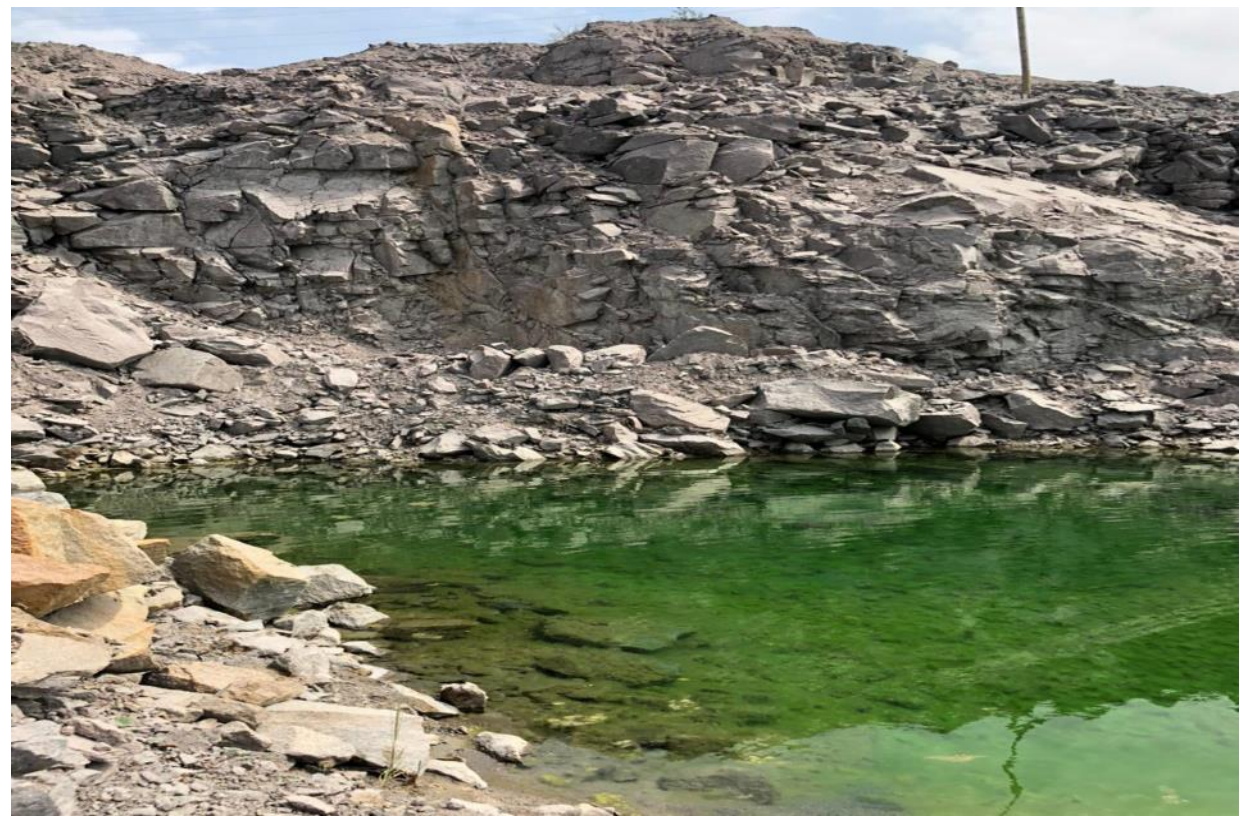

Рис. 3. Техногенные озера в карьере - зумпф для накопления дренажных вод.

[Fig. 3. Man-made lakes in a quarry - a sump for drainage water accumulation.]

Сработка водоносных горизонтов при открытой добыче полезных ископаемых является значимой экологической проблемой для горнодобывающих районов. Качество воды, сбрасываемое в поверхностные водотоки с дренажных емкостей, как правило, не соответствует санитарно-гигиеническим стандартам. Среди экологических проблем также следует отметить буровзрывные работы, которые сопровождаются сейсмическими нагрузками в радиусе до 120 км, пылением и загрязнением прилегающих к карьеру территорий.

В процессе работы выездного круглого стола участники семинара сумели ознакомиться с основными способами разработки гранитного сырья и теми экологическими проблемами, которые возникают при функционировании данных карьеров.

Второй круглый стол был посвящен акватории Воронежского водохранилища и его экологическим проблемам. В работе Данного круглого стола принял участие Депутат Государственной Думы Федерального собрания Российской Федерации VII созыва, председатель комитета Госдумы по природным ресурсам, собственности и земельным отношениям Николаев Н. П. Круглый стол проходил на площадке б/ц Сабуров, располагающегося на берегу Воронежского водохранилища. Участники мероприятия имели возможность визуального обзора акватории уникального искусственного водоема, который практически полностью раз- мещается в пределах крупной городской агломерации г. Воронеж. Обсуждались проблемы загрязнения Воронежского водохранилища, его влияние на р. Дон

Третий выездной круглый стол состоялся в пределах особо охраняемой природной территорий Галичья гора. Здесь рассматривались вопросы экологического мониторинга природных территорий, в особенности большой интерес вызвал сейсмический мониторинг, который позволяет фиксировать и природные сейсмические колебания и вибрационные воздействия техногенного характера.

Заключительная часть семинара представляла собой встречу всех участников и обсуждение полученных результатов. Несомненно, что мероприятия данного формата представляют большой научный и практический интерес. Они позволяют на международном уровне не только обменяться результатами фундаментальных и методических разработок в области обеспечения экологической безопасности техногенно нагруженных территорий, но и осуществить выезды на конкретные объекты с целью анализа эффективности внедрения природоохранных рекомендаций на отдельных объектах.

Конфликт интересов: Авторы декларируют отсутствие явных и потенциальных конфликтов интересов, связанных с публикацией настоящей статьи.
Косинова Ирина Ивановна - д. Г.-м. н., профессор, Воронежский государственный университет, Воронеж, Российская Федерация; E-mail: kosinova777 @ yandex.ru; ORCID http://orcid.org/0000-0002-5439-5197

Автор прочитал и одобрил окончательный вариант рукописи.
Irina I. Kosinova - Dr. habil. in Geol.-Min., Professor, Voronezh State University, Voronezh, Russian Federation;

E-mail: kosinova777@yandex.ru;

ORCID http://orcid.org/0000-0002-5439-5197

Author has read and approved the final manuscript. 